\title{
Returns to Investment in Distance Learning: the Case of Greece
}

\author{
George Agiomirgianakis ${ }^{1}$,Theodore Lianos ${ }^{2}$, Nicholas Tsounis ${ }^{3}$ \\ ${ }^{1}$ Professor, Economic Analysis and Policy Lab, Hellenic Open University, School of Social Sciences, Parodos \\ Aristotelous 18, Perivola, 26335-Patras, Greece \\ ${ }^{2}$ Professor Emeritus, Athens University of Business and Economics, Greece \\ ${ }^{3}$ Professor, Department of International Trade, Technological Institute of Western Macedonia, Adjunct Faculty, \\ Hellenic Open University, Fourka Area, 52100 - Kastoria, Greece \\ Correspondence: George Agiomirgianakis, Professor, Hellenic Open University, School of Social Sciences, \\ Parodos Aristotelous 18, Perivola, 26335-Patras, Greece.
}

Received: January 9, 2019

doi:10.5539/ibr.v12n3p94
Accepted: January 29, 2019

Online Published: Februrary 11, 2019

URL: https://doi.org/10.5539/ibr.v12n3p94

\begin{abstract}
In this paper we extend the literature on the rate of return to investment in Higher Education towards studies in distance learning Universities. In particular, we explore the difference in returns between graduates of a distance learning university (the Hellenic Open University - HOU) and applicants that were excluded by this university's random selection process and did not study elsewhere. The data set was extracted from a database compiled from responses to a questionnaire which was part of a survey concerning HOU (the only Distance-learning University in Greece). A modified Mincer type model was estimated with fixed effects. Our findings suggest that graduates that have obtained a first degree from HOU enjoy a rate of return to education of about $8 \%$ higher than the rate of return obtained by those high school graduates that were not selected by this university. Moreover, Master's degree graduates get about a $16.5 \%$ higher rate of return to education relatively to those applicants that were not selected for studies in HOU and did not study elsewhere. Additionally, our findings also show that the rates of return for higher education are high even after the 2008 economic crisis. These results suggest a straightforward policy implication: a distance learning University may not only be considered as a second chance to education for mature students, often facing time and budget restrictions, but, it may also be seen as a worthwhile private investment enabling a much higher private return. Moreover, from policymakers' point of view, a distance learning university can be seen as a vehicle to reduce income inequalities and thus increase social mobility.
\end{abstract}

Keywords: economic policy, returns to investment in education, distance learning, higher education, Mincer Equation

\section{JEL codes: I26; J24}

\section{Introduction}

The empirical investigation of the theory of human capital linking wages with the years of education and working experience was first introduced by J. Mincer (1958) and led to an exponential growth of literature on the effects of Human capital on remuneration of workers, employability, distribution of income, labour mobility across regions and countries, social mobility between generations, technology and economic development. In the literature section below we present and discuss the results from several empirical studies examining the returns to investment in higher education worldwide and in Greece.

In the human capital literature about the effects of higher education on the labour market there is a general consensus that graduates enjoy better prospects than lower education level graduate and the private returns to investment in university studies in Greece vary from approximately $5 \%$ to $15 \%{ }^{1}$. This paper aspires to provide further empirical evidence to this strand of literature by estimating the difference between the education returns of the graduates from the only distance learning University in Greece and high school graduates. This is something that has not been done by any other study. The findings on education returns will be useful not only for prospect Open University students but also to the stakeholders exercising educational policy in Greece. The

\footnotetext{
${ }^{1}$ Please see the 'Literature Review section', below.
} 
research question addressed is the estimation of the returns to investment in education of the Hellenic Open University (HOU) graduates either to, on one hand, the first or the master's degrees and, on the other hand, to those applicants that were not selected for studies in HOU and who did not study elsewhere. The data used was extracted from 2,112 questionnaires that were collected with field research in $2014^{2}$.

The paper has the following structure: Section 2, presents a literature review on the empirical findings for the returns to investment in education in Greece. Section 3, formulates the model for measuring education returns, the estimating methodology, the description of the variables and the description of our data-set. Section 4, discusses the estimation results and presents the returns to investment in education in Greece for the Hellenic Open University. Finally, Section 5, concludes and presents the policy implications of our findings.

\section{Literature Review}

There is a plethora of studies estimating the rate of return to higher education since the early works by Mincer in the '50s. A recent non exhaustive list includes Guo, M. et. al. (2019), D'Aguiar, S. et. al. (2016), Naylor et al (2015), Oreopoulos et al. (2013); Psacharopoulos, G. (2012), Harmon C. (2011) and Heinrichet al (2005). In the latter an excellent survey for different time periods can be found. The first studies for Greece, for estimating the rate of return to higher education was done by Leibestein (1967) for 1965, Psacharopoulos (1982) and Lambropoulos and Psacharopoulos (1992). The former found a "low" rate of return, while the latter two found a rate of return of $15 \%$ for $1960,14 \%$ for $1964,15.1 \%$ for $1975,10.5 \%$ for $1977,13.6 \%$ for 1981 and $10.2 \%$ for 1985 .

Patrinos (1995) and Kanellopoulos (1997) for 1977 and 1987-8 have found very similar rates of return, namely $5.6 \%$ and 5.4\%, respectively while, Magoula and Psacharopoulos (1999), using data for 1993, estimated the rate of return for 1993 to be 6.3\%. Tsakloglou and Cholezas (2001) estimated the rate of return for men and women for 1974, 1988 and 1995 and found them to be $9.3 \%, 6.2 \%$ and $8.7 \%$ for men for the respective years and $11.9 \%$, $8.0 \%$ and $10.4 \%$ for women. More recently, Prodromidis and Prodromidis (2008) have found that the rate of return for men and women for 1988, 1994 and 1998 is 3.9\%, 6.3\% and 7.6\% for men for the respective years and $8.1 \%, 6.2 \%$ and $14.1 \%$ for women.

Mitrakos et al. (2010) have estimated the rate of return of twenty years after graduation for several professions. Their estimates range between $4 \%$ and $10,5 \%$, while it is $9.3 \%$ for a postgraduate degree and $7.8 \%$ for a doctorate. Finally, Livanos and Pouliakas (2011) have found that the rates of return for 2003 for men and women were $5.9 \%$ and $5.0 \%$ respectively for the first degree, $7.6 \%$ and $19.2 \%$ for a Master's and surprisingly negative for a Ph.D.,-2.0\% for men and $-6.6 \%$ for women. Further, a recent sectoral study for MBA graduates found that MBA studies help graduates to find enriched jobs with increasing compensation over time (Mihail et.al. 2014).

From the above finding, it is seen that for the period 1974 to 1977 there is a clear negative trend of the rates return. Comparing the results of the above studies for years before and after 1981 it appears that the rate of return has been reduced by approximately fifty percent. This decline is probably related to the high rates of growth of the economy and a rather limited supply of university graduates in the first period and the reversal of these conditions in the second.

Second, the rates of return for higher education remain high even after the 2008 sovereign debt crisis, but the recession has brought about some changes in the ranking of the various professions.

Third, the returns to education for postgraduate studies are significantly higher than the rates of return of the first degree.

In the literature on the rates of return to education no attention has be given so far, to the best of our knowledge, on the private rates of return obtained by graduates of distance learning universities This is a shortcoming, which does not conform with the rapid expansion of Distance Learning (DL) programmes in higher education observed worldwide during the last two decades ${ }^{3}$. Our paper is addressing this issue offering some interesting findings to graduates, to potential students of a DL university, as well as, to policymakers that design educational policy measures.

\section{Methodology and Data}

\subsection{The Mincer Equation}

Along the lines suggested by Psacharopoulos et al. (2004) and Bunzel et.al. (2008) we use the Mincer equation

${ }^{2}$ Please see the 'Survey Structure and Data description' section below for further details.

${ }^{3}$ See e.g. Goodman et al (2016) who emphasize the role of distance learning methodology as it "may open opportunities for populations who would not otherwise pursue education". 
(1958, 1974) for the estimation of the private returns of investment (in schooling years) to education. This equation is popular in the literature measuring the returns to the human capital invested by individuals. It is based on a typical model of investment in human capital where people invest in human capital to maximize the present value of future returns. The Mincer equation, although half a century old, is still used in several variations as it describes quite well the data in the real world. The dependent variable, wages, is in logarithm, as opposed to independent variables that are the years of education and working experience. In order to find the different rates of return for the different education levels a dummy variable is used for each level of education in the Mincer equation. Thus, the equation takes the form:

$$
\ln W=b_{0}+b_{1} X+b_{2} X^{2}+a_{1} d_{1}+a_{2} d_{2}+a_{3} d_{3}+a_{4} d_{4}
$$

where $\ln W$ is the logarithm of wages, $X$ the years of working experience, $d_{1}, d_{2}, d_{3}$ and $d_{4}$ represent the four levels of education: no education, primary, secondary, and university education, respectively. From (1) the private rates of return between levels of education are calculated by the estimated coefficients of the dummy variables ${ }^{4}$.

Given that we do not have primary education graduates in our sample, (1) is modified as:

$$
\ln W_{t, i}=b_{0}+b_{1} X_{t, i}+b_{2} X_{t, i}^{2}+a_{2} D_{2, i}+a_{3} D_{3, i}+a_{4} D_{4, i}+u_{t, i}
$$

where $i$ is individual $\mathrm{i}, t=1, \ldots, 8$ (4 year before graduation and 4 years after), $\boldsymbol{D}_{2}=1$ for secondary school graduates, $D_{3}=1$ for first degree holders, and $D_{4}=1$ for Master's holders.

\subsection{Survey Structure and Data Description}

The data set for the variables in (2) was extracted from a database compiled from responses to a questionnaire which was part of a survey concerning the Hellenic Open University (the only Distance-learning University in Greece). This survey was the focal point of a research project primarily aiming at gathering information (both quantitative and qualitative) on the career paths of HOU graduates. The survey period was from June to October 2015. It was aimed at respondents who graduated in 2007, 2008, and 2009. This means the questions were asked 6-8 years after graduation. Graduates came from three academic programs, namely Management Studies, Computer Science, and Civilisation and Humanities Studies. Each HOU program consists of 12 modules. Students are enrolled after a random selection process among applicants who must be 23 years of age or older. Students pay fees and tuition for each module they take.

In order to create our data set, a detailed questionnaire was made electronically available to HOU graduates and high school graduates that have applied for a position in HOU but they excluded by the random selection process. Using the electronic interface of the survey, a total of 2,112 responses to the questionnaire were gathered out of which 1,791 were used by the research in this paper ${ }^{5} .1,057$ responses were gathered from graduates of HOU (both for graduate and postgraduate studies), while 734 responses came from individuals who applied for studies in the HOU but they excluded by the random selection process.

Thus our data set consists of 1,791 individuals who have either obtained their first degree or master's degree from HOU or those individuals that were not selected for study in HOU though they had applied for a position at the same time with the HOU's graduates. The former have graduated in the $2007-2009$ period while the latter were selected from those who applied for but not selected four years prior to the period of graduation of the former, i.e during 2003-2005, with working experience. Therefore, high school graduates included in our data set

\footnotetext{
${ }^{4}$ Psacharopoulos and Patrinos (2004) suggest that the returns to education should be calculated per schooling year. Therefore, they suggest that the difference between the estimated coefficients be divided by the typical number of schooling years. We suggest that returns to education levels would be more appropriate because is not the years of study but the qualification obtained that has an impact on one's wage (or unemployment probability).

${ }^{5}$ The remaining number of questionnaires (321 questionnaires) concerns traditional university graduates which were out of the scope of this study.
} 
are individuals without university education and are about the same stage of their lives with the first degree graduates. Furthermore, since, our sample consists of wages for four years before graduation, a HOU graduate is considered as a graduate only for the last four years in the sample. For the first four years D2=1, D3=0 and he is classified with the high school graduates.

To summarise the following three categories of individuals were extracted from the questionnaire database ${ }^{6}$ :

A. HOU first degree graduates; 712 valid questionnaires were completed in this category

B. Applied for a HOU degree but not selected, secondary education graduates; 734 valid questionnaires were completed in this category.

C. Master's degree HOU graduates; 345 valid questionnaires were completed in this category

Each individual, either graduate of HOU or not, was asked to report remuneration and employment data for a period of four years before (and including) their graduation year and four years after that. Wage data were deflated so that no loss of comparability issues are raised. Therefore, the sample size for the above three categories consisted of 14,328 observations. Descriptive statistics of the sample on the three above groups are presented in the Appendix.

As we have already mentioned earlier, students of HOU were selected randomly and in an open to the public, selection ceremony. This selection process was observed by university authorities, ministerial authorities and district attorney. This selection ceremony was taking place on December 15th of each year and selected students could enrol in the choice of their studies from the following October. Although, the university is called Open University, the number of student applications in the last 20 years exceeded the number of students that the university could educate. As a result of this restriction the random selection process, described above, was adopted.

\subsection{Methodology for Estimating the Returns to Investment for HOU Graduates}

It is obvious that (2) has to be estimated with panel data because it concerns with graduates (subscript $i$ ) and for each graduate we have 8 observations for different consecutive years -four before graduation and four after(subscript $t$ ). There are different methods for estimating panel data models: (a) with fixed effects (FE), (b) with random effects (RE) and (c) with neither fixed nor random effects. The FE method is used when the interest is only for the analysis of the effects of variables that change over time. If the error terms are correlated, then the use of FE is not appropriate (the confidence intervals of the estimated coefficients would not be correct) and another method should be used, that of the random effects (RE). The choice between the two methods is made using the Hausman test where the null hypothesis is that the model has RE while the alternative is that it has $\mathrm{FE}^{7}$. It is concluded that the null hypothesis should be rejected and (2) should be estimated using the FE model. The final model for estimation becomes:

$$
\ln W_{t, i}=b_{0}+b_{1} X_{t, i}+b_{2} X_{t, i}^{2}+a_{3} D_{3, i}+a_{4} D_{4, i}+\sum_{i=2}^{n} c_{i} \Phi_{i}+u_{t, i}
$$

where $\Phi$ are $n-1$ dummy variables and $n$ is the total number of questionnaires. Each of these dummies absorbs the effects on the dependent variable that are specific to each individual. So, the heterogeneity among persons that has not been modelled into (2) is taken into account

From the estimates for the coefficients of $D_{3}$ and $D_{4}$ the difference in the rates of return between levels of education for HOU graduates relatively to high school graduates can be calculated ${ }^{8}$. The coefficient on $D_{3}$ shows the difference in the returns of education between high school diploma and HOU's first degree and the same applies for the coefficient on $D_{4}$, i.e. it shows the difference in the returns of education between high school diploma and HOU's master's degree.

By using a Wald test the statistical significance of the difference in coefficients of $D_{3}$ and $D_{4}$ can be tested. The hypothesis is:

$$
H_{0}: a_{3}=a_{4}, H_{1}: a_{3} \neq a_{4}
$$

\footnotetext{
${ }^{6}$ The questionnaire used for the survey is in Greek and is available upon request from the authors.

${ }^{7}$ The chi-square statistic from the Hausman test was 293.9 and it was statistically significant at 0.00 level of significance.

${ }^{8}$ The D2 variable cannot be included in the estimated equation because it will cause perfect multicollinearity.
} 
If the null hypothesis in (4) is rejected at, at least, 0.05 level of statistical significance then it will be concluded that there is a difference in the rates of return for the first degree studies and the rates of return for the master's graduates of the same University.

\section{Results}

The estimation results from the estimation of (3) are presented in Table 1 below.

Table 1. Estimation results on the returns to education for HOU relative to high school graduates

\begin{tabular}{|c|c|c|c|}
\hline Number of obs & & $10,943^{9}$ & \\
\hline F-statistic & & $78.70^{* * *}$ & \\
\hline $\mathrm{R}^{2}$ adj & & 0.763 & \\
\hline Variables & Coefficient & Standard error & p-value \\
\hline$X$ & $0.02864^{* *}$ & 0.00293 & 0.000 \\
\hline$X^{2}$ & $0.00022^{*}$ & 0.00012 & 0.040 \\
\hline$D_{3}$ & $0.07869^{* *}$ & 0.01237 & 0.000 \\
\hline$D_{4}$ & $0.16501^{* *}$ & 0.02338 & 0.000 \\
\hline Constant & $9.64431^{* *}$ & 0.01761 & 0.000 \\
\hline
\end{tabular}

Source: Authors' estimates

Notes. The results shown are from the estimation of (3) using fixed effects. Two stars indicate statistical significance at less than $1 \%$ level of significance and one star indicates statistical significance at less than $5 \%$ level of significance ${ }^{10}$.

Table 1 shows that the rate of return of university education is higher in the case of graduates holding Master's degree (8.6\% higher relative to the first degree holders ${ }^{11}$ and $16.5 \%$ higher than high school graduates) than those with Bachelor's degree, a result verified by literature see e.g. Liwinski,J. (2016).

Our results are in line with previous studies in Greece, see among others e.g. Kanellopoulos and Cholezas (2014), showing that returns to education for postgraduate studies are significantly higher than the rates of return of the first degree and, also, that the rates of return for higher education are high even after the 2008 the starting point of the eight years economic crisis in Greece.

To draw conclusions on this point from our results, a final test should be made: the statistical significance in the difference in returns for undergraduate and postgraduate studies of HOU graduates should be tested. Therefore, to test the hypothesis in (4) the Wald test has been used. The F-statistic for (4) had a value of 29.88 and it was statistically significant at 0.000 level of statistical significance. Therefore, the null hypothesis is rejected and the alternative is adopted12. Consequently, for both first and master's degree holders there is a difference in the returns to investment (in schooling years) between the Distance Learning and high school graduates in Greece. Thus, although Kanellopoulos and Cholezas (2014) findings were based on data of the periods 2004-2007 and 2010-2012 while our results are based on data for the period 2007-2013 $3^{13}$ we do confirm their finding that returns to education for postgraduate studies are significantly higher than the rates of return of the first degree and, also, that the rates of return for higher education are high even after the 2008. This result is a strong indication that university graduates are better hedged against unemployment and/or wage instability relative to less educated individuals. This finding is in line with Kanellopoulos et. al (2013) study that have found that although the Greek debt crisis has increased the probability of unemployment for all, those with more education have suffered less and higher education graduates enjoy better prospects in the labour market than lower education level graduates.

\section{Conclusions and Policy Implications}

In this paper the rate of returns to investment in Higher Education for studies in distance learning universities has been measured for Greece. Specifically, we measure the return to investment in education for both undergraduate and graduate studies of the only distance learning university (the Hellenic Open University - HOU) that is in

\footnotetext{
${ }^{9}$ Due to missing questionnaire data, the actual sample size used was 10,943 observations.

${ }^{10}$ The model also passes the RESET test for functional form misspecification (this is also called Ramsey test). The $\chi^{2}$-statistic had a value of 0.98 with a p-value of 0.32 . Therefore, the null hypothesis cannot be rejected and it is concluded that the model is correctly specified.

${ }^{11}$ This is calculated by the difference in the values between the coefficients estimated for $D_{3}$ and $D_{4}$.

${ }^{12}$ That is, the alternative hypothesis is adopted with zero margin of error.

${ }^{13}$ The first graduates of HOU from our sample were from 2007.
} 
operation in Greece. The returns to investment in education were estimated using a Mincer equation. The data used was extracted from questionnaires collected with field research performed within the framework of a HOU research project.

We proceed our analysis by first estimating a Mincer equation and our findings show that the rate of return to investment in education for the first degree HOU graduates is $7.9 \%$ higher than that of the high school graduates that are at the same stage in their lives and more than double (16.5\%) for the Master's degree graduates relatively to the high school graduates.

Finally, we test for the statistical significance in the difference in returns for undergraduate and postgraduate studies in HOU graduates by using the Wald test. This test shows that the difference in returns between first degree graduates and master's graduates is $8.6 \%$ and it is statistically different from zero.

From a policy perspective point of view, our results are interesting for the Ministry of education that is responsible for the educational policy of higher education in Greece and also for the HOU administration authorities. This is so, because our findings suggest that a distance learning University may not only be considered as a second chance to education for mature students often facing time and budget restrictions, but, it may also be seen as a worthwhile investment enabling significant private returns. Therefore, distance learning universities may be used by policy authorities as a vehicle to reduce income inequalities and increasing social mobility. On the other hand, our results also offer a useful insight into whether an investment in university education is worthwhile from the individual's point of view that would like to study but face either time/budget restrictions or, equally important, is not able to have a daily psychical presence in their university.

\section{Acknowledgments}

This research was carried out as a research project co-financed by the European Union (European Social Fund$E S F)$ and Greek national funds through the Operational Program "Education and Lifelong Learning" of the National Strategic Reference Framework (NSRF). Financial support is gratefully acknowledged.

\section{References}

Bunzel, H., Christensen, B., Neumann, G., \& Robin, J. (2008). Structural Models of Wage and Employment Dynamics, 275, Elsevier.

D'Aguiar, S., \& Harrison, N. (2016). Returning from earning: UK graduates returning to postgraduate study, with particular respect to STEM subjects, gender and ethnicity. Journal of Education and Work, 29(5), 584-613. https://doi.org/10.1080/13639080.2014.1001332

Goodman, J., Melkers, J., \& Pallais, A. (2016). Can Online Delivery Increase Access To Education? Working Paper 22754. National Bureau of Economic Research October. http://www.nber.org/papers/w22754

Guo, M., Zhang, Y., \& Ye, J. (2019) "Does a foreign degree pay -The return to foreign education in China". Review of Development Economics, 23(1). https://doi.org/10.1111/rode.12550

Harmon, C. (2011). Economic Returns to Education: What We Know, What We Don't Know, and Where We Are Going - Some Brief Pointers. IZA Policy Paper No. 29.

Heinrich, G., \& Hildebrand, V. (2005). Returns to Education in the European Union: a reassessment from comparative data. European Journal of Education, 40(1). https://doi.org/10.1111/j.1465-3435.2005.00207.x

Kanellopoulos, C. N. (1997). Public-Private Wage Differentials in Greece. Applied Economics, 29, 1023-1032. https://doi.org/10.1080/000368497326417

Kanellopoulos, N., \& Cholezas, I. (2014), Private Returns to Education in Greece: The Effects of Recession, Institute of Labor. Athens.

Kanellopoulos, N., Mitrakos, T., Tsakloglou, P., \& Cholezas, I. (2013). The Effects of the Current Crisis on Private Returns to Education in Greece. Oikonomiko Deltio, 2013, 35-67.

Lambropoulos, H., \& Psacharopoulos, G. (1992). Educational Expansion and Earnings Differentials in Greece. Comparative Educational Review, 36, 52-70. https://doi.org/10.1086/447081

Leibenstein, H. (1967). Rates of Return to Education in Greece, Economic Development Report, No. 94, Harvard University.

Livanos, I., \& Pouliakas, K. (2011). Wage Returns to University Disciplines in Greece: are Greek Higher Education Degrees Trojan Horses? Education Economics, 19(4), 411-445.

https://doi.org/10.1080/09645290903546363 
Liwinski, J. (2016). Does It Pay To Study Abroad? Evidence from Poland. 6th Economics \& Finance Conference, OECD Headquarters, 06 September 2016, Paris and University of Warsaw, working papers 25/2016 (216). https://doi.org/10.20472/EFC.2016.006.014

Magoula, T., \& Psacharopoulos, G. (1999). Schooling and Monetary Rewards in Greece: An Over-education False Alarm? Applied Economics, 31, 1589-1597. https://doi.org/10.1080/000368499323111

Mihail, D., \& Kloutsiniotis, P. (2014). The impact of an MBA on managerial skills and career advancement: the Greek case. The International Journal of Management Education, 12, 212-222. https://doi.org/10.1016/j.ijme.2014.04.002

Mincer, J. (1958). Investments in Human Capital and Personal Income Distribution. Journal of Political Economy, 66(4), 281-302. https://doi.org/10.1086/258055

Mincer, J. (1974). Schooling, Experience and Earnings. New York: Columbia University Press.

Mitrakos, T., Tsakloglou, P., \& Cholezas, I. (2010). Factors Determining wages in Greece with Emphasis on Wages of University Graduates. Oikonomiko Deltio, 2010, 7-39 ( In Greek).

Naylor R., Smith J., \& Telhaj, S. (2015). Graduate Returns, Degree Class Premia and Higher Education Expansion in the UK, CEP Discussion Paper No 1392 November 2015.

Oreopoulos P., \& Petronijevic, U. (2013). Making College Worth It: A Review of Research on the Returns to Higher Education. NBER Working Paper No. 19053. https://doi.org/10.3386/w19053

Patrinos, H. A. (1995). Socioeconomic Background, Schooling, Experience, Ability and Monetary Rewards in Greece. Economics of Education Review, 14(1), 85-91. https://doi.org/10.1016/0272-7757(94)00028-5

Prodromidis, K., Prodromidis, P. (2008). Returns to education: the Greek experience, 1998-1999. Applied Economics, 40, 1023-1030. https://doi.org/10.1080/00036840600771197

Psacharopoulos, G. (1982). Earnings and Education in Greece, 1960-1977. European Economic Review., 17(3), 333-347. https://doi.org/10.1016/S0014-2921(82)80068-8

Psacharopoulos, G. (2012). The Value of Investment in Education: Theory, Evidence, and Policy. Journal of Education Finance, 32(2), O'Leary issue (fall 2006), 113-136.

Psacharopoulos, G., \& Patrinos, H. A. (2004). Human Capital and Rates of Return. Chapter 1 in Johnes, G., Johnes, J., (eds). International Handbook on the Economics of Education. Cheltenham: Edward Elgar Publishing, pp. 1-57. https://doi.org/10.4337/9781845421694.00006

Tsakloglou, P., \& Cholezas, I. (2001). Greece. In C. Harmon, I. Wolker, N. Westergaard-Nielsen (eds), Education and Earnings in Europe. Choltenham.

\section{Appendix A}

\section{Descriptive statistics on the sample}

Table A1. Sample means of wages by category

\begin{tabular}{cccc}
\hline Category & Mean & Standard Error & Number of observations \\
\hline A & 16443.88 & 153.4891 & 4423 \\
B & 14653.15 & 175.5433 & 4404 \\
C & 17294.99 & 192.2931 & 2116 \\
\hline
\end{tabular}

Source: Authors' calculations

Table A2. Sample means of years of working experience by category

\begin{tabular}{cccc}
\hline Category & Mean & Standard Error & Number of observations \\
\hline A & 12.94382 & 0.1029862 & 4423 \\
B & 11.50835 & 0.0917844 & 4404 \\
C & 14.08587 & 0.1338238 & 2116 \\
\hline
\end{tabular}

Source: Authors' calculations

\section{Copyrights}

Copyright for this article is retained by the author(s), with first publication rights granted to the journal.

This is an open-access article distributed under the terms and conditions of the Creative Commons Attribution license (http://creativecommons.org/licenses/by/4.0/). 